\title{
Assessment of radiant temperature in a closed incubator
}

\author{
Pauline Décima $\cdot$ Erwan Stéphan-Blanchard • Amandine Pelletier • \\ Laurent Ghyselen - Stéphane Delanaud - Loïc Dégrugilliers • \\ Frédéric Telliez · Véronique Bach · Jean-Pierre Libert
}

Received: 16 November 2010/Accepted: 23 November 2011/Published online: 10 December 2011

(C) The Author(s) 2011. This article is published with open access at Springerlink.com

\begin{abstract}
In closed incubators, radiative heat loss $(R)$ which is assessed from the mean radiant temperature $\left(\bar{T}_{r}\right)$ accounts for $40-60 \%$ of the neonate's total heat loss. In the absence of a benchmark method to calculate $\bar{T}_{r}$-often considered to be the same as the air incubator temperature-errors could have a considerable impact on the thermal management of neonates. We compared $\bar{T}_{r}$ using two conventional methods (measurement with a black-globe thermometer and a radiative "view factor" approach) and two methods based on nude thermal manikins (a simple, schematic design from Wheldon and a multisegment, anthropometric device developed in our laboratory). By taking the $\bar{T}_{r}$ estimations for each method, we calculated metabolic heat production values by partitional calorimetry and then compared them with the values calculated from $\dot{V}_{\mathrm{O}_{2}}$ and $\dot{V}_{\mathrm{CO}_{2}}$ measured in 13 preterm neonates. Comparisons between the calculated and measured metabolic heat production values showed that the two conventional methods and Wheldon's manikin underestimated $R$, whereas when using the anthropomorphic thermal manikin, the simulated versus clinical difference was not statistically
\end{abstract}

Communicated by George Havenith.

P. Décima ( $₫)$ · E. Stéphan-Blanchard · A. Pelletier .

L. Ghyselen · S. Delanaud · L. Dégrugilliers · F. Telliez ·

V. Bach · J.-P. Libert

Unité de Recherche PériTox EA 4285-UMI 01 INERIS,

Faculté de Médecine, Université de Picardie Jules Verne,

3 rue des Louvels, 80036 Amiens Cédex1, France

e-mail: pauline.decima@u-picardie.fr

L. Ghyselen · L. Dégrugilliers

Médecine Néonatale et Réanimation Pédiatrique Polyvalente, Centre Hospitalier Universitaire Nord, Place Victor Pauchet, 80054 Amiens Cédex1, France significant. In conclusion, there is a need for a safety standard for measuring $\bar{T}_{r}$ in a closed incubator. This standard should also make available estimating equations for all avenues of the neonate's heat exchange considering the metabolic heat production and the modifying influence of the thermal insulation provided by the diaper and by the mattress. Although thermal manikins appear to be particularly appropriate for measuring $\bar{T}_{r}$, the current lack of standardized procedures limits their widespread use.

Keywords Thermal manikin - Thermoregulation · Radiant heat loss $\cdot$ Premature neonates $\cdot$ Nursing care

\section{Introduction}

For neonates nursed in closed incubators, providing an optimal thermal environment (currently defined as thermoneutrality) is a priority not only for survival and growth but also for the stability of various physiological functions. At thermoneutrality, the brain's body temperature control centre does not receive significant thermal inputs from skin and/or internal receptors. This corresponds to a range of ambient temperature within which body temperature is mainly regulated by changing peripheral blood flow, with no regulatory changes in metabolic heat production or skin evaporative heat loss. A normal body temperature is maintained by the balance between metabolic heat production $(M)$ and body heat dissipation through conduction $(K)$, evaporation $(E)$, convection $(C)$, radiation $(R)$ and evaporative $\left(E_{\text {resp }}\right)$ and convective $\left(C_{\text {resp }}\right)$ respiratory heat losses. Today, optimizing and monitoring this optimal thermal environment in closed incubators remains a challenge. In practice, the thermal performance of incubator focuses solely on air temperature $\left(T_{\mathrm{a}}\right)$, since this parameter 
can be controlled easily and accurately. However, this type of control does not take account of all the environmental parameters such as air velocity that modifies convective and evaporative heat losses, incubator wall temperatures which alter radiant heat exchange and air humidity which changes evaporative skin cooling. In addition, the reduction of the thermal exchanges due to the diaper is never taken into account. Even though radiative heat loss (which depends on the mean radiant temperature, $\bar{T}_{r}$ ) accounts for as much as 40-60\% of the neonate's body heat losses (Hey and Mount 1967; Swyer 1978; Wheldon 1982; Bell and Rios 1983; Hammarlund et al. 1986) in closed incubators, there are currently no recommendations on how $\bar{T}_{r}$ should be measured (in terms of both the method used and the degree of accuracy required).

Researchers are now working to better understand the thermal environment in incubators and thus improve the level of care for high-risk neonates. This work involves the development of computer programs which model the various body heat losses and gains (Helder et al. 1976; Bell and Rios 1983; Adams et al. 2000; Lyon and Oxley 2001; Museux et al. 2008) and algorithms which define an environmental (or operative) temperature on the basis of $T_{\mathrm{a}}$ and $\bar{T}_{r}$ (Perlstein et al. 1976; Atherton et al. 1994), rather than $T_{\mathrm{a}}$ only. Recently, computational fluid dynamics (CFD) has also been successively used to describe the thermal interaction between the neonate body and its environment (Ginalski et al. 2007, 2008). The CFD models' reliability was confirmed by comparing the results with literature data on heat losses from neonates and thermal manikins. In addition to this research on the thermal environment during nursing care, other mathematical models (Jardine 1992; Bolton et al. 1996; Agourram et al. 2010) have been designed for the assessment of critical situations, which, for ethical reasons, cannot be studied in neonates (such as exposure to severe cold or heat stress). The key input components of all these programs are the skin, air, and mean radiant temperatures and the humidity. Given that $\bar{T}_{r}$ is not measured in currently marketed incubators, most studies analysing or modelling radiative heat transfer adopt alternative approaches in which $\bar{T}_{r}$ is considered to be equal to the inner wall and mattress surface temperatures (Perlstein et al. 1976; Atherton et al. 1994; Adams et al. 2000; Lyon and Oxley 2001) or the incubator temperature (Jardine 1992).

In the present study, $\bar{T}_{r}$ was assessed in four fundamentally different procedures based on either standard equations or thermal manikins. The first ("GT") method involved the use of a conventional, matt-black, copper globe thermometer. This method is commonplace in the assessment of thermal environments for human occupation but has rarely been used in incubators (Silverman et al.
1966; Hey 1968). The second ("VF") approach used body and incubator wall "view factors" to calculate the plane radiant temperature. The third method (WH) is a mathematical equation developed by Wheldon (1982) via a manikin representing a neonate by simple geometrical body shapes. The fourth and last manikin (MAN) approach used a multisegment, anthropomorphic, thermal model developed in our laboratory; it represents a small-forgestational-age neonate and takes into account the body's thermal heterogeneity and different segment shapes.

To the best of our knowledge, no comparative study of these different approaches has ever been published. Indeed, given the lack of a benchmark or standardized validation procedure, there is no evidence to suggest that any one method is better than the others in predicting $\bar{T}_{r}$. With a view to solving this problem, we compared the calculated and clinical values of metabolic heat production. The clinical values $\left(M_{\text {ref }}\right)$ were evaluated from the measured values of $\dot{V}_{\mathrm{O}_{2}}$ and $\dot{V}_{\mathrm{CO}_{2}}$, using a well-established method (indirect respiratory calorimetry). Metabolic heat production $(M)$ calculated by partitional calorimetry (Adams et al. 2000; Museux et al. 2008) consists in calculating the sum of the body heat losses $\left(C+K+E+E_{\text {resp }}+C_{\text {resp }}\right)$ and $R$ calculated from the $\bar{T}_{r}$ value estimated by each of the four approaches mentioned above. This comparison is based on the fact that at thermoneutrality, there is a thermal equilibrium between the neonate's body and the environment in which $M$ balances the heat losses [ $M$ or $M_{\text {ref }}=$ $\left.-\left(R+C+K+E+E_{\text {resp }}+C_{\text {resp }}\right)\right]$. We considered that the most appropriate approach for measuring $\bar{T}_{r}$ would most reliably predict the clinical values $\left(M_{\text {ref }}\right)$ calculated from respiratory gas exchanges.

\section{Methods}

Assessment of the mean radiant temperature $\left(\bar{T}_{r}\right)$ : laboratory tests

The experiments were performed in the laboratory in a climatic chamber in which the room and wall temperatures were $24.87 \pm 0.26$ and $24.52 \pm 0.17^{\circ} \mathrm{C}$, respectively; this corresponds to the ambient conditions usually encountered in a neonatal intensive care unit (NICU).

$\bar{T}_{r}$ was measured in a convectively heated, closed incubator (the ISIS $+{ }^{\circledR}$ from Médipréma, Tours, France). The incubator was operated in air temperature mode control, in which the incubator air temperature was randomly set at five values: $29.39 \pm 0.01,30.00 \pm 0.03,30.99 \pm$ $0.01,32.01 \pm 0.01$ and $33.02 \pm 0.01^{\circ} \mathrm{C}$ (corresponding to the range of values encountered in the NICU). The incubator's inner surface temperatures were continuously 
measured by thermistor probes (Yellow Springs Instruments; Yellow Springs, $\mathrm{OH}$, series $409 \mathrm{~A}$, accuracy $\pm 0.1^{\circ} \mathrm{C}$ ) placed in the centre of each wall. The mattress surface temperature was recorded by five attached thermistors (4 in the corners and one in the centre of the mattress's upper surface). All the temperature sensors had been previously calibrated in a water bath at temperatures ranging from 20 to $45^{\circ} \mathrm{C}$. The air velocity was measured with a hot-globe anemometer (Testo 490 from Testo, Forbach, France, accuracy $\pm 0.05 \mathrm{~m} \mathrm{~s}^{-1}$ ) and was always below $0.15 \mathrm{~m} \mathrm{~s}^{-1}$ (indicating the absence of forced convection). Air velocity and incubator temperature were measured at a point $10 \mathrm{~cm}$ above the centre of the mattress upper surface, as recommended by American National Standards (1997).

\section{Conventional methods}

The GT method used a black-globe thermometer (diameter $15 \mathrm{~cm}$, wall thickness $0.6 \mathrm{~mm}$, emissivity 0.97 ), in the centre of which a temperature sensor is fixed (Standard ISO 7726 2002). The globe was positioned $10 \mathrm{~cm}$ above the centre of the mattress. $\bar{T}_{r}$ was calculated from the globe temperature $\left(T_{\mathrm{g}},{ }^{\circ} \mathrm{C}\right)$ and the air incubator temperature $\left(T_{\mathrm{a}}\right.$, ${ }^{\circ} \mathrm{C}$ ) by applying the following equation used under natural convection conditions:

$\bar{T}_{r}=\left[\left(T_{\mathrm{g}}+273\right)^{4}+0.4 \times 10^{8}\left|T_{\mathrm{g}}-T_{\mathrm{a}}\right|^{0.25}\left(T_{\mathrm{g}}-T_{\mathrm{a}}\right)\right]^{0.25}$ -273 .

The VF approach was based on weighting the surface temperatures of the incubator's inner walls and mattress with "view factors" which depend on the body's projected surface area on the incubator's walls. Each view factor depends on (a) the wall's dimensions, (b) its orientation relative to the neonate and (c) the wall-body distance. In the present study, the "view factors" for each incubator wall and mattress were calculated as follows:

$F=\frac{1}{\pi} \int \frac{\cos \theta_{2}}{r^{2}} \mathrm{~d} A_{2} \int \cos \theta_{1} \mathrm{~d} A_{1}$,

where $\mathrm{d} A_{1}$ is a small surface area on the neonate, $\mathrm{d} A_{2}$ a small surface area on the incubator wall, $r$ the distance between $\mathrm{d} A_{1}$ and $\mathrm{d} A_{2}, \theta_{1}$ the angle between the normal to the area $\mathrm{d} A_{1}$ and the line between $\mathrm{d} A_{1}$ and $\mathrm{d} A_{2}$ and $\theta_{2}$ is the angle between the normal to the area $\mathrm{d} A_{2}$ and the line between $\mathrm{d} A_{1}$ and $\mathrm{d} A_{2}$. Integration was performed over the surface areas of the incubator walls and the body.

$\bar{T}_{r}$ was calculated by weighting the wall and mattress temperatures according to each calculated "view factor", as follows:

$$
\begin{aligned}
\bar{T}_{r}= & 0.226 T_{\mathrm{TW}}+0.136\left(T_{\mathrm{LW}}+T_{\mathrm{RW}}\right)+0.036\left(T_{\mathrm{FW}}\right. \\
& \left.+T_{\mathrm{BW}}\right)+0.429 T_{\mathrm{m}},
\end{aligned}
$$

where $T_{\mathrm{TW}}, T_{\mathrm{LW}}, T_{\mathrm{RW}}, T_{\mathrm{FW}}$ and $T_{\mathrm{BW}}$ are the surface temperatures of the top, left lateral, right lateral, front and rear walls, respectively, and $T_{\mathrm{m}}$ the temperature of the mattress surface $\left({ }^{\circ} \mathrm{C}\right)$.

As expected, the calculated projected area factors were greatest for the incubator wall above the neonate and for the mattress.

\section{Methods using manikins}

The WH method used the equation defined by Wheldon (1982) on the basis of measurements of incident radiation with thermopile radiometers at 10 positions over the surface of a nude simple-shaped manikin. The latter schematically represents a $3.3-\mathrm{kg}$ neonate (i.e. a simple combination of smooth cylindrical forms: a spherical head, a cylindrical trunk and 4 cylindrical limbs):

$\bar{T}_{r}=1.43+0.761 T_{\mathrm{a}}+0.169 T_{\text {room }}$,

where $T_{\mathrm{a}}$ and $T_{\text {room }}$ are the air temperatures in the incubator and the nursery room, respectively (in ${ }^{\circ} \mathrm{C}$ ). The manikin's surface temperature was uniform over the different body segments.

Finally, the MAN approach used a black-painted manikin ( 6 body segments) with locally controlled surface temperatures. The manikin represents a small-for-gestational-age neonate with a body surface area of $0.086 \mathrm{~m}^{2}$ and a simulated weight of $900 \mathrm{~g}$. The body shape reproduces the fingers, toes, eyes, mouth, ears and nose-each with the appropriate body angles. It has been extensively validated and described in detail elsewhere (Elabbassi et al. 2004; Belghazi et al. 2006; Museux et al. 2008). The nude manikin was placed in a relaxed supine position on the mattress, with the face turned to the side (with the arms parallel to and $1.0 \mathrm{~cm}$ away from the trunk and the legs spread apart at $1.7 \mathrm{~cm}$ from the axis). The anthropomorphic thermal manikin takes account of an infant's anatomy, since the latter is an important factor in heat loss (especially within the complex thermal environment of an incubator). The head and limbs can be manipulated to reproduce postural changes. In contrast to other models described in the literature, our manikin's surface temperature was not uniformly constant and accurately reflects the observed thermal heterogeneity for the various body regions. Hence, we were able to set precise, constant surface temperatures for each of the six segments. The surface temperatures of the manikin were recorded by thermistors (CTN Sciences, $10 \mathrm{k} \Omega$ at $25^{\circ} \mathrm{C}$, accuracy: $0.1^{\circ} \mathrm{C}$ ) protected from radiant energy by an aluminium foil patch.

Under steady-state thermal situations, the electric heat power supplied to each segment's resistance wires balances the heat lost to the environment. In contrast to the 
Table 1 Temperatures of the anthropomorphic thermal manikin

\begin{tabular}{|c|c|c|c|c|c|c|c|c|c|c|c|}
\hline $\begin{array}{l}\text { Temperature } \\
\text { Segment }\end{array}$ & talt & $\begin{array}{l}\text { Set temp. } 1 \\
29.39 \pm 0.01\end{array}$ & Delta & $\begin{array}{l}\text { Set temp. } 2 \\
30.00 \pm 0.03\end{array}$ & Delta & $\begin{array}{l}\text { Set temp. } 3 \\
30.99 \pm 0.01\end{array}$ & Delta & $\begin{array}{l}\text { Set temp. } 4 \\
32.01 \pm 0.01\end{array}$ & Delta & $\begin{array}{l}\text { Set temp. } 5 \\
33.02 \pm 0.01\end{array}$ & Del \\
\hline \multirow[t]{2}{*}{$\mathrm{T}$ head } & B & $5.30 \pm 0.01$ & 0.04 & 0.01 & 0.07 & $35.30 \pm 0.03$ & 0.09 & 0.05 & 0.05 & 0.03 & 0.01 \\
\hline & $\mathrm{F}$ & $35.34 \pm 0.05$ & & $35.37 \pm 0.05$ & & $35.39 \pm 0.02$ & & $35.40 \pm 0.01$ & & 0.02 & \\
\hline \multirow[t]{2}{*}{$\mathrm{T}$ trunk } & B & $34.80 \pm 0.01$ & 0.01 & $34.80 \pm 0.01$ & 0.00 & $34.80 \pm 0.01$ & 0.01 & $34.80 \pm 0.01$ & 0.02 & $34.81 \pm 0.02$ & 0.03 \\
\hline & $\mathrm{F}$ & 34.8 & & 34.8 & & .03 & & .04 & & .05 & \\
\hline \multirow[t]{2}{*}{$\mathrm{T}$ right arm } & B & $32.29 \pm 0.03$ & 0.02 & $32.30 \pm 0.02$ & 0.01 & .02 & 0.08 & .05 & 0.15 & .02 & 0.03 \\
\hline & $\mathrm{FC}$ & $32.31 \pm$ & & $32.31 \pm 0.05$ & & $32.39 \pm 0.03$ & & \pm 0.05 & & .04 & \\
\hline \multirow[t]{2}{*}{$\mathrm{T}$ left arm } & B & $32.25 \pm$ & 0.06 & $32.28 \pm 0.04$ & 0.07 & $32.30 \pm 0.01$ & 0.10 & $32.38 \pm 0.04$ & 0.02 & $32.38 \pm 0.02$ & 0.02 \\
\hline & $\mathrm{FC}$ & $32.31 \pm 0.04$ & & $32.35 \pm 0.05$ & & $32.40 \pm 0.01$ & & $32.40 \pm 0.03$ & & $32.40 \pm 0.03$ & \\
\hline \multirow[t]{2}{*}{$\mathrm{T}$ right leg } & B & $34.39 \pm 0.05$ & 0.03 & $34.39 \pm 0.05$ & 0.04 & $34.41 \pm 0.05$ & 0.03 & $34.42 \pm 0.05$ & 0.03 & $34.44 \pm 0.05$ & 0.04 \\
\hline & $\mathrm{FC}$ & $34.42 \pm 0.05$ & & $34.43 \pm 0.05$ & & $34.44 \pm 0.04$ & & $34.45 \pm 0.05$ & & $34.48 \pm 0.05$ & \\
\hline \multirow[t]{2}{*}{ T left leg } & B & $34.25 \pm 0.05$ & 0.04 & $34.27 \pm 0.05$ & 0.03 & $34.29 \pm 0.03$ & 0.01 & $34.30 \pm 0.02$ & 0.01 & $34.31 \pm 0.03$ & 0.03 \\
\hline & $\mathrm{FC}$ & $34.29 \pm 0.03$ & & $34.30 \pm 0.02$ & & $34.30 \pm 0.02$ & & $34.31 \pm 0.03$ & & $34.34 \pm 0.05$ & \\
\hline \multirow[t]{2}{*}{$T_{\mathrm{s}}$} & B & $34.32 \pm 0.03$ & 0.03 & $34.32 \pm 0.02$ & 0.04 & $34.33 \pm 0.03$ & 0.05 & $34.36 \pm 0.03$ & 0.04 & $34.39 \pm 0.03$ & 0.03 \\
\hline & $\mathrm{FC}$ & $34.35 \pm 0.04$ & & $34.36 \pm 0.04$ & & $34.38 \pm 0.03$ & & $34.40 \pm 0.03$ & & $34.42 \pm 0.04$ & \\
\hline
\end{tabular}

Mean values $\pm 1 \mathrm{SD}$ of surface temperatures $\left({ }^{\circ} \mathrm{C}\right)$ of each segment (head, trunk, right and left arms, right and left legs and skin) of the black (B) and foil-covered (FC) manikins for the five incubator set temperatures. Values are mean $\pm 1 \mathrm{SD}$. Delta $\left({ }^{\circ} \mathrm{C}\right)$ is the local surface temperature difference between the $\mathrm{B}$ and $\mathrm{FC}$ manikins. $T_{\mathrm{s}}\left({ }^{\circ} \mathrm{C}\right)$ is the mean surface temperature

Wheldon's method, the heat fluxes were measured across the manikin's surface area as a whole.

The heat power $\left(\mathrm{P}, \mathrm{W} \mathrm{m}^{-2}\right)$ supplied to the manikin was measured and fed into the following equation:

$P=\sigma \varepsilon A_{r}\left[\left(\bar{T}_{\mathrm{s}}+273\right)^{4}-\left(\bar{T}_{r}+273\right)^{4}\right]+C+K$,

where $\sigma$ is the Stephan-Boltzmann's constant $(5.67 \times$ $\left.10^{-8} \mathrm{~W} \mathrm{~m}^{-2} \mathrm{~K}^{-4}\right), \varepsilon$ the emissivity of the black surface (0.97), $A_{r}$ the percentage of effective radiating surface area (0.66; Agourram et al. 2010), $\bar{T}_{r}$ and $\bar{T}_{\mathrm{s}}$ the mean radiant and the mean surface temperatures, respectively $\left({ }^{\circ} \mathrm{C}\right)$, and $C$ and $K$ are the convective and conductive heat losses, respectively $\left(\mathrm{W} \mathrm{m}^{-2}\right)$.

In a second step, we tightly wrapped the manikin in highly reflective aluminium foil (emissivity $\varepsilon_{\mathrm{a}}=0.05$ ), in order to minimize the risk of increasing the degree of thermal insulation by entrapped air. The heat power $\left(P_{\mathrm{a}}\right.$, $\mathrm{W} \mathrm{m}^{-2}$ ) supplied to the foil-covered manikin was:

$P_{\mathrm{a}}=\sigma \varepsilon_{\mathrm{a}} A_{r}\left[\left(\bar{T}_{\mathrm{s}}+273\right)^{4}-\left(\bar{T}_{r}+273\right)^{4}\right]+C+K$.

The surface temperatures of the black and foil-covered manikins were held constant, so as to prompt the same convective and conductive heat losses to the environment.

Under these conditions and at any given incubator temperature, the equation becomes:

$P-P_{\mathrm{a}}=\sigma A_{r}\left[\left(\bar{T}_{\mathrm{s}}+273\right)^{4}-\left(\bar{T}_{r}+273\right)^{4}\right]\left(\varepsilon-\varepsilon_{\mathrm{a}}\right)$

and the mean radiant temperature $\bar{T}_{r}\left({ }^{\circ} \mathrm{C}\right)$ can be expressed as:

$\bar{T}_{r}=\left[\left(\bar{T}_{s}+273\right)^{4}+\left(P_{a}-P\right) /\left(\sigma\left(\varepsilon-\varepsilon_{a}\right) A_{r}\right)\right]^{1 / 4}-273$.
The local surface temperatures are shown in Table 1. The mean surface temperatures (weighted according to the local temperatures and the relative surface area of each segment) were $34.34 \pm 0.03$ and $34.38 \pm 0.04^{\circ} \mathrm{C}$ for the black and foil-covered manikins, respectively-very close to the values measured with infrared thermometry on preterm neonates nursed at thermoneutrality in a closed incubator (see validation of the different approaches: clinical tests). Irrespective of the experimental conditions, the variability in the surface temperatures from one trial to another (i.e. the coefficient of variation, derived from the ratio between the standard deviation and the mean) was always below $0.03 \%$. The local and mean temperature differences between the black and foil-covered manikins did not exceed $0.15^{\circ} \mathrm{C}$ (set temperature 4 , right arm region) and $0.05^{\circ} \mathrm{C}$, respectively, showing that the degree of insulation provided by the aluminium foil was negligible. The slightly higher mean surface temperatures recorded for the foil-covered manikin resulted in slight overestimations of the convective $(C)$ and conductive $(K)$ heat losses (i.e. the heat power supplied to the manikin). In our experiments, these overestimates [assessed using Eqs. 12 and 14 (see below) and ranging between 0 and $0.004 \mathrm{~W} \mathrm{~m}^{-2}$ ] were negligible.

To assess the repeatability of the measurements, five trials were performed for each of the five incubator air temperatures and each of the four methods (i.e. 100 measurements in all). The experiments with the globe thermometer and the various manikin configurations were performed in random order. After a period of at least 45 min necessary to reach a steady state, each measurement lasted for $1 \mathrm{~h}$. 
Validation of the different approaches: clinical tests

\section{Subjects}

The clinical study was performed in the neonatal intensive care unit at Amiens University Hospital, France. Neonates were only enrolled after their parents had been informed of the protocol and had given their written consent. The study protocol had been approved by the Picardy Regional Ethics Committee. Thirteen preterm neonates were recruited (mean \pm 1 SD birth weight 1,580 $\pm 263 \mathrm{~g}$, gestational age $30.7 \pm 2.3$ weeks, postnatal age $39 \pm 9$ days). The mean body mass at the time of the study was $2,100 \pm 131 \mathrm{~g}$. Neonates with neurological disorders, apnoea episodes longer than $20 \mathrm{~s}$ or bradycardia (defined as a drop in instantaneous heart rate below 90 beats $\mathrm{min}^{-1}$ ) or on special diet were not included in the study. All the included neonates were stable, healthy and gained weight during the study. None received oxygen or phototherapy at the time of the study. They were nursed at thermoneutrality in a skin temperature-servo-controlled ISIS $+{ }^{\circledR}$ from Médipréma (Tours, France), i.e. an incubator similar to that used in the laboratory for the assessment of $\bar{T}_{r}$. The incubator air temperature was monitored using a skin probe covered by an aluminium patch and taped on the midline between the umbilicus and the hepatic body region. The servo-control set-point was $36.8-37.0^{\circ} \mathrm{C}$, which corresponds to a thermoneutral environment (Oliver 1965; Scopes and Ahmed 1966; Hey and Mount 1967; Knobel et al. 2010). For preterm infants, the minimal values of oxygen consumption were found for this value of abdominal skin temperature (Malin and Baumgart 1987). The neonates wore a diaper (made out of cotton and a plastic film and covering $15.4 \%$ of the total body skin surface area, weight $29.8 \mathrm{~g}$ ) and lay in a supine position on a hard, plastic foam mattress covered by two cotton sheets (total thickness $5 \mathrm{~cm}$ ).

Air velocity, temperature and humidity were measured at a point situated $10 \mathrm{~cm}$ above the centre of the mattress, as recommended by corresponding American National Standards (1997). During the tests, the mean incubator air temperature was $31.9 \pm 0.7^{\circ} \mathrm{C}$ and the mean relative air humidity [recorded with a resistive thin-film sensor (RHU 207 from General Eastern, Mulhouse, France)] was $43 \pm 10 \%$. The air velocity was always below $0.15 \mathrm{~m} \mathrm{~s}^{-1}$.

All the experiments were performed on the morning in a quiet room adjacent to the NICU. The room was climatecontrolled (room temperature $23-25^{\circ} \mathrm{C}$, relative air humidity 30-58\%) and protected against strong sunlight. The mean radiant temperature in the room (measured with a globe thermometer) and the air temperature never differed by more than $0.5^{\circ} \mathrm{C}$. The environmental temperatures were similar to those encountered during laboratory tests.
The body segments' skin temperatures were measured non-invasively with an infrared camera [the Thermovision 550 from AGEMA (Danderyl, Sweden); sensitivity $\pm 0.1^{\circ} \mathrm{C}$ at $30^{\circ} \mathrm{C}$, accuracy $\pm 2^{\circ} \mathrm{C}$ between 20 and $\left.250^{\circ} \mathrm{C}\right]$. Infrared scans were made through an aperture in the roof and the doors of the incubator's sidewalls over short periods of time (30-60 s). The camera's emissivity was calibrated with respect to a thermistor probe taped to the skin of the abdominal region before each experiment. Image analysis software (ThermaCAM ${ }^{\mathrm{TM}}$ Reporter, FLIR Systems, Boston, MA) was used to calculate the surface temperatures from the different coloured areas (outlined as geometrical shapes). For each neonate, five pictures were obtained for each body segment and the datasets were independently evaluated by two experimenters. The overall mean skin temperature $\bar{T}_{\text {sk }}$ was calculated as the average of local skin temperatures, weighted according to each body segment's the relative surface area (Museux et al. 2008):

$\bar{T}_{\text {sk }}=0.17 T_{\text {head }}+0.34 T_{\text {legs }}+0.34 T_{\text {trunk }}+0.15 T_{\text {arms }}$.

Given that the neonate was lying in the supine position on the mattress, it was not possible to measure the skin temperature under the diaper and for the back (in contact with the mattress). In order to reduce colour distortion errors near to body edges, we limited our analysis of the thermograms to anterior and lateral projections.

\section{Metabolic heat production, calculated by partitional calorimetry $(M)$}

For each infant, metabolic heat production $\left(M, \mathrm{~W} \mathrm{~m}^{-2}\right)$ was determined by partitional calorimetry. At thermoneutrality, $M$ balances the body heat losses to the environment:

$M=-\left(R+C+K+E+E_{\text {resp }}+C_{\text {resp }}\right)$,

where $R, C, K$ and $E$ are the radiative, convective, conductive and skin evaporative heat losses, respectively, and $E_{\text {resp }}$ and $C_{\text {resp }}$ are the evaporative and convective respiratory heat losses, respectively. All body heat exchanges were expressed in $\mathrm{W} \mathrm{m}^{-2}$. The goal of this method was to calculate $M$ by modulating the value of one type of heat transfer ( $R$, derived from $\bar{T}_{r}$ assessed with the four methods described above) while the other transfers $(C+K+$ $E+E_{\text {resp }}+C_{\text {resp }}$, which do not depend on $\bar{T}_{r}$ ) remain constant, i.e., the difference in calculated metabolic heat production values only depends on $\bar{T}_{r}$.

Radiative heat loss was calculated from the StefanBoltzmann's law:

$R=\sigma \varepsilon A_{r}\left[\left(\bar{T}_{r}+273\right)^{4}-\left(\bar{T}_{\mathrm{sk}}+273\right)^{4}\right] F_{\mathrm{cl}}$, 
where $\sigma$ is the Stefan-Boltzmann's constant $\left(5.67 \times 10^{-8}\right.$ $\mathrm{W} \mathrm{m}{ }^{-2} \mathrm{~K}^{-4}$ ), $\varepsilon$ the skin emissivity (0.97), $\bar{T}_{r}$ and $\bar{T}_{\mathrm{sk}}$ the mean radiant and skin temperatures $\left({ }^{\circ} \mathrm{C}\right)$, respectively, $A_{r}$ the percentage of the neonate's surface area exchanging heat by radiation and $F_{\mathrm{cl}}$ is the reduction factor for dry heat exchanges due to the diaper (0.81; Museux et al. 2008). The effect of clothing is described as a reduction factor compared to nude conditions.

In order to take account of the body surface area involved in radiative heat exchanges, calculations of $R$ were made with the neonate in a relaxed $\left(A_{r}=0.66\right)$ and a spread-eagle $\left(A_{r}=0.74\right)$ positions, i.e. the body positions commonly adopted by neonates nursed at thermoneutrality. In the spread-eagle position, $A_{r}$ was calculated as the proportion of the effective radiating surface area assessed for sedentary adult (0.84) (Kubaha et al. 2004) minus the fraction of the surface area in contact with the mattress (0.095) (Agourram et al. 2010).

The convective heat loss depends on the difference between the incubator air $\left(T_{a}\right)$ and mean skin temperatures $\left(\bar{T}_{\text {sk }}\right)$ :

$C=h_{\mathrm{c}} A_{\mathrm{c}}\left(T_{\mathrm{a}}-\bar{T}_{\mathrm{sk}}\right) F_{\mathrm{cl}}$,

where $h_{\mathrm{c}}$ is the convective heat transfer coefficient $\left(2.99\left|T_{a}-\bar{T}_{s k}\right|^{0.25}, \mathrm{~W}^{\circ} \mathrm{C}^{-1} \mathrm{~m}^{-2}\right)$ and $A_{\mathrm{c}}$ is the percentage of the neonate's surface area exchanging heat by convection. The value was determined by taking into account the area in contact with the mattress (0.095) and the proportion of the upper part of the trunk covered by the diaper (0.092): $A_{\mathrm{c}}=1-0.095-0.092=0.81$.

Skin evaporative heat loss $(E)$ was calculated as follows:

$E=h_{\mathrm{e}} A_{\mathrm{e}} \omega\left(P_{\mathrm{sH}_{2} \mathrm{O}}-P_{\mathrm{aH}_{2} \mathrm{O}}\right) F_{\mathrm{pcl}}$,

where $\omega$ is the skin wettedness (0.06 in a thermoneutral environment, when no sweating occurs) (Gagge 1937), $A_{\mathrm{e}}$ the percentage of the neonate's surface area exchanging heat by evaporation $\left(A_{\mathrm{c}}=A_{\mathrm{e}}\right), P_{\mathrm{SH}_{2} \mathrm{O}}-P_{\mathrm{aH}_{2} \mathrm{O}}$ the difference between the skin vapour pressure at saturation $\left(P_{\mathrm{SH}_{2} \mathrm{O}}\right)$ and the air $\left(P_{\mathrm{aH}_{2} \mathrm{O}}\right)$ partial water vapour pressures $(\mathrm{kPa})$, $F_{\text {pcl }}$ the reduction factor for latent heat loss due to the diaper 0.83 (Museux et al. 2008) and $\mathrm{h}_{\mathrm{e}}$ is the evaporative heat transfer coefficient $\left(\mathrm{W} \mathrm{m}^{-2} \mathrm{kPa}^{-1}\right)$, which is calculated from $h_{\mathrm{c}}$ using Lewis' equation $\left(h_{\mathrm{e}}=16.7 h_{\mathrm{c}}\right.$ ) (Lewis 1922).

Conductive heat loss $(K)$ between the skin $\left(\bar{T}_{\mathrm{sk}},{ }^{\circ} \mathrm{C}\right)$ and the mattress surface $\left(T_{\mathrm{m}},{ }^{\circ} \mathrm{C}\right)$ temperatures was calculated as follows:

$K=h_{\mathrm{K}} A_{\mathrm{k}}\left(T_{\mathrm{m}}-\bar{T}_{\mathrm{sk}}\right)$,

where $h_{\mathrm{K}}$ is the conductive heat transfer coefficient $\left(0.21 \mathrm{~W} \mathrm{~m}^{-2}{ }^{\circ} \mathrm{C}^{-1}\right.$; Apedoh et al. 1999) and $A_{\mathrm{k}}$ is the percentage of the neonate's surface area exchanging heat by conduction $(0.095)$.

The convective $\left(C_{\text {resp }}\right)$ and evaporative $\left(E_{\text {resp }}\right)$ respiratory heat losses were calculated as follows:

$C_{\text {resp }}=\left(0.277 \dot{V}_{\mathrm{E}}\left(T_{\mathrm{e}}-T_{\mathrm{i}}\right) C_{\mathrm{p}}\right) / A_{\mathrm{D}}$

$E_{\text {resp }}=\left(0.277 \dot{V}_{\mathrm{E}} \delta\left(m_{\mathrm{e}}-m_{\mathrm{i}}\right)\right) / A_{\mathrm{D}}$,

where $C_{\mathrm{p}}$ is the heat capacity of air $\left(1.044 \mathrm{~kJ} \mathrm{~kg}^{-1}{ }^{\circ} \mathrm{C}^{-1}\right)$, $T_{\mathrm{e}}-T_{\mathrm{i}}$ the temperature difference between expired $\left(T_{\mathrm{e}}\right)$ and inspired $\left(T_{\mathrm{i}}=T_{\mathrm{a}}\right)$ air $\left({ }^{\circ} \mathrm{C}\right), \delta$ the latent heat of vaporization $\left(2.43 \mathrm{~kJ} \mathrm{~g}^{-1}\right.$ of water), $\dot{V}_{\mathrm{E}}$ the pulmonary ventilation $\left(\mathrm{kg} \mathrm{h}^{-1}\right)$ and $m_{\mathrm{e}}-m_{\mathrm{i}}$ is the difference in water content $\left(\mathrm{kg}\right.$ water kg dry $\left.\mathrm{air}^{-1}\right)$ between expired $\left(m_{\mathrm{e}}\right)$ and inspired air $\left(m_{\mathrm{i}}\right)$. The values were converted in watt (since $1 \mathrm{~kJ} \mathrm{~h}^{-1}=0.277 \mathrm{~W}$ ).

The total body surface area $\left(A_{\mathrm{D}}, \mathrm{cm}^{2}\right)$ was calculated from Boyd's (1935) equation while taking account of each neonate's body mass $\left(W_{\mathrm{t}}, \mathrm{g}\right)$ :

$A_{\mathrm{D}}=4.688 \mathrm{~W}_{\mathrm{t}}^{(0.8168-0.0154 \log \mathrm{Wt})}$.

$T_{\mathrm{e}}$ was calculated with Hanson's equation cited by Adams et al. (2000):

$T_{\mathrm{e}}=32.6+0.066 T_{\mathrm{a}}+32 \mathrm{H}_{2} \mathrm{O}_{\text {in }}$,

where $\mathrm{H}_{2} \mathrm{O}_{\text {in }}$ is inspired water vapour in $\mathrm{g} \mathrm{L}^{-1}$.

The water constants in inspired $\left(m_{\mathrm{i}}\right)$ and expired $\left(m_{\mathrm{e}}\right)$ air were calculated as recommended by the Standard ISO 7726 (2002):

$m=0.622 \times\left(P_{\mathrm{H}_{2} \mathrm{O}} /\left(P_{\mathrm{B}}-P_{\mathrm{H}_{2} \mathrm{O}}\right)\right)$,

where $P_{\mathrm{B}}$ is the barometric pressure $(\mathrm{kPa})$ and $P_{\mathrm{H}_{2} \mathrm{O}}$ is the partial pressure of water vapour in inspired $\left(P_{\mathrm{H}_{2} \mathrm{Oi}}\right)$ or expired $\left(P_{\mathrm{H}_{2} \mathrm{Oe}}\right)$ air $(\mathrm{kPa})$, expressed as follows:

$P_{\mathrm{H}_{2} \mathrm{O}}=0.611 \mathrm{e}^{((17.27 T) /(T+237.3))}$,

where $T$ is the temperature of expired $\left(T_{\mathrm{e}}\right)$ or inspired $\left(T_{\mathrm{i}}=T_{\mathrm{a}}\right)$ air.

The calculations were based on the individual values of skin temperature (measured by infrared thermometry; $34.14 \pm 0.10^{\circ} \mathrm{C}$, on average) of incubator air temperature $\left(31.93 \pm 0.73^{\circ} \mathrm{C}\right)$ and of relative air humidity $(43 \pm 10 \%)$. The abdominal skin temperature was $36.70 \pm 0.20^{\circ} \mathrm{C}$, on average.

\section{Metabolic heat production measured by indirect respiratory calorimetry $\left(M_{\text {ref }}\right)$}

Metabolic heat production by each neonate was assessed using a well-established method (indirect respiratory calorimetry). An open-circuit respiratory device was used to measure the concentrations of $\mathrm{O}_{2}$ and $\mathrm{CO}_{2}$ in the outflowing air captured by a silicon face mask (reference No. 0, Glaxo 
Wellcome, Les Ulis, France) attached to a pneumotachograph (Statice Sante ${ }^{\circledR}$ Corp., Besançon, France). The mask was fitted to the infant and positioned as recommended by Stocks et al. (1989) and care was taken to avoid leakage (total instrumental dead space $1.35 \mathrm{ml}$ ). The flow signal was converted into an analogue signal via a pressure transducer (DP45-16, Validyne Corp, Northridge, CA, USA; accuracy $\pm 20 \mathrm{mmH}_{2} \mathrm{O}$ ) driven by a Gould amplifier (Carrier 13-G465, Gould Inc., Cleveland, OH). The tidal volume was integrated to yield breath-by-breath measurements of pulmonary ventilation. The pneumotachograph was calibrated before each experiment by injection of known air volumes at different rates with a syringe. $\mathrm{O}_{2}$ and $\mathrm{CO}_{2}$ in the outflowing air were measured online and breath-by-breath with a mass spectrometer (MGA 1100, Perkin-Elmer, Pomona, CA, USA, variability below $10 \%$, full scale $\mathrm{O}_{2} 100 \%$ ). The gas was drawn into the analyser at $18 \mathrm{ml} \mathrm{min}{ }^{-1}$ through a capillary tube inserted into the lumen of the pneumotachograph.

Volumes were corrected to standard temperature $\left(0^{\circ} \mathrm{C}\right)$, dry pressure $(101.3 \mathrm{kPa}) . \dot{V}_{\mathrm{O}_{2}}$ and $\dot{V}_{\mathrm{CO}_{2}}$ were calculated online. Measurements were made at least $1 \mathrm{~h}$ after a bottle feed (to minimize postprandial changes in $M$ ) and during well-established quiet or active sleep (as judged from electroencephalograms and eye movements). Sleep stages were scored in 30-s intervals according to CurziDascalova and Mirmiran (1996). At least 4 min elapsed before the start of data recording, ensure that no change occurred in the state of alertness. Metabolic heat production $\left(M_{\mathrm{ref}}, \mathrm{W} \mathrm{m}^{-2}\right)$ was assessed using Lusk's (1928) equation:

$M_{\text {ref }}=\left(4.425+1.429 \operatorname{RER} \dot{V}_{\mathrm{O}_{2}}\right) A_{\mathrm{D}}^{-1}$,

where RER is the respiratory exchange ratio between $\dot{V}_{\mathrm{O}_{2}}$ and $\dot{V}_{\mathrm{CO}_{2}}$ (dimensionless), $A_{\mathrm{D}}$ the skin surface area of the neonate $\left(\mathrm{m}^{2}\right)$ and $\dot{V}_{\mathrm{O}_{2}}$ and $\dot{V}_{\mathrm{CO}_{2}}$ are expressed in $\mathrm{L} \mathrm{h}^{-1}$.

In order to take account of sleep stage differences in metabolic activity, $M_{\text {ref }}$ was calculated with $\dot{V}_{\mathrm{O}_{2}}$ and $\dot{V}_{\mathrm{CO}_{2}}$ values measured within each sleep stage (at least 2-6 times) and weighted according to the relative duration of quiet or active sleep, expressed as a proportion of total sleep time.

\section{Statistical analysis}

$\bar{T}_{r}$ values measured with the four methods were compared in a non-parametric Kruskal-Wallis test.

Radiative heat loss and metabolic heat production were compared using a non-parametric Friedman test and then by a Wilcoxon post hoc test. The threshold for statistical significance was set to 0.05 . Values are given as mean \pm 1 SD.

\section{Results}

Determination of the mean radiant temperature $\left(\bar{T}_{r}\right)$ using the different approaches

Table 2 shows (a) the mean values of the environmental parameters recorded in the incubator, (b) the heat power supplied to the black and the foil-covered manikin and (c) the $\bar{T}_{r}$ values estimated with the different approaches when the incubator air temperature $\left(T_{\mathrm{a}}\right)$ varied between 29.39 and $33.02^{\circ} \mathrm{C}$. The fluctuations in the heat power supply to the manikin over $1 \mathrm{~h}$ ranged between 1.00 and $2.20 \%$ for the black manikin and between 1.40 and $5.30 \%$ for the foilcovered manikin. $\bar{T}_{r}$ values were always below the incubator temperature; the smallest differences were observed for the GT method (ranged between 0.48 and $0.84^{\circ} \mathrm{C}$ ) and the greatest were seen with the MAN method (ranged between 2.06 and $3.22^{\circ} \mathrm{C}$ ). $\bar{T}_{r}$ values differed significantly from one approach to another $(H=29.430, p<0.001)$ and as a function of the different incubator air temperature levels $(H=66.323, p<0.001)$.

Since it is impossible to measure $\bar{T}_{r}$ during the clinical tests with the neonate, we fitted a linear equation to the relationship (degrees of freedom $=23$ ) between $\bar{T}_{r}$ and values of $T_{\mathrm{a}}$ centred around $31.93^{\circ} \mathrm{C}$ (which corresponds to the mean air temperature recorded in the incubator). For a room temperature of $23-25^{\circ} \mathrm{C}$, the relationships were:

Globe thermometer $\left(r^{2}=0.997 ; \mathrm{SE}=0.010\right)$ :

$$
\bar{T}_{r}=0.881\left(T_{a}-31.93\right)+31.44
$$

View factors $\left(r^{2}=0.993 ; \mathrm{SE}=0.014\right)$ :

$$
\bar{T}_{r}=0.833\left(T_{a}-31.93\right)+30.39
$$

Wheldon's equation $\left(r^{2}=0.999 ; \mathrm{SE}=0.002\right)$ :

$$
\overline{T_{r}}=0.760\left(T_{a}-31.93\right)+29.88
$$

Anthropomorphic manikin $\left(r^{2}=0.905 ; \mathrm{SE}=0.049\right)$ :

$$
\overline{T_{r}}=0.724\left(T_{a}-31.93\right)+29.00
$$

where SE is the standard error of the slope.

Comparison of measured $\left(M_{\text {ref }}\right)$ and calculated $(M)$ metabolic heat production values

The different modes of body heat loss were calculated using partitional calorimetry (Fig. 1). The radiative body heat losses were assessed for the neonates in relaxed and spreadeagle positions from the respective $\bar{T}_{r}$ values calculated in Eqs. 22-25 from incubator air temperatures measured for each neonate. The sum of $\left(C+K+E+E_{\text {resp }}+C_{\text {resp }}\right)$ was $18.28 \pm 4.13 \mathrm{~W} \mathrm{~m}^{-2}$, whereas for GT, VF, WH and 
Table 2 Environmental temperatures in the incubator

\begin{tabular}{|c|c|c|c|c|c|}
\hline$T_{\mathrm{a}}\left({ }^{\circ} \mathrm{C}\right)$ & $\begin{array}{l}\text { Set temp. } 1 \\
29.39 \pm 0.01\end{array}$ & $\begin{array}{l}\text { Set temp. } 2 \\
30.00 \pm 0.03\end{array}$ & $\begin{array}{l}\text { Set temp. } 3 \\
30.99 \pm 0.01\end{array}$ & $\begin{array}{l}\text { Set temp. } 4 \\
32.01 \pm 0.01\end{array}$ & $\begin{array}{l}\text { Set temp. } 5 \\
33.02 \pm 0.01\end{array}$ \\
\hline$T_{\mathrm{RW}}$ & $26.96 \pm 0.13$ & $27.27 \pm 0.14$ & $27.80 \pm 0.17$ & $28.40 \pm 0.16$ & $28.98 \pm 0.17$ \\
\hline$T_{\mathrm{LW}}$ & $27.34 \pm 0.09$ & $27.69 \pm 0.09$ & $28.28 \pm 0.07$ & $28.93 \pm 0.07$ & $29.55 \pm 0.06$ \\
\hline$T_{\mathrm{TW}}$ & $28.75 \pm 0.02$ & $29.36 \pm 0.05$ & $30.37 \pm 0.03$ & $31.42 \pm 0.03$ & $32.45 \pm 0.04$ \\
\hline$T_{\mathrm{FW}}$ & $27.60 \pm 0.05$ & $28.02 \pm 0.06$ & $28.71 \pm 0.05$ & $29.45 \pm 0.05$ & $30.19 \pm 0.05$ \\
\hline$T_{\mathrm{BW}}$ & $28.40 \pm 0.02$ & $28.99 \pm 0.04$ & $30.00 \pm 0.04$ & $31.03 \pm 0.06$ & $32.06 \pm 0.07$ \\
\hline$T_{\mathrm{m}}$ & $28.62 \pm 0.10$ & $29.30 \pm 0.13$ & $30.12 \pm 0.08$ & $30.95 \pm 0.03$ & $31.88 \pm 0.13$ \\
\hline$P$ & $102.98 \pm 0.84$ & $97.00 \pm 0.93$ & $86.04 \pm 0.73$ & $73.42 \pm 0.73$ & $59.12 \pm 0.41$ \\
\hline$P_{\mathrm{a}}$ & $75.71 \pm 0.41$ & $70.69 \pm 1.04$ & $61.73 \pm 0.73$ & $51.57 \pm 0.84$ & $41.97 \pm 0.52$ \\
\hline$T_{\mathrm{g}}$ & $29.02 \pm 0.11$ & $29.61 \pm 0.18$ & $30.49 \pm 0.11$ & $31.37 \pm 0.18$ & $32.40 \pm 0.11$ \\
\hline$T_{\mathrm{r}} \mathrm{GT}$ & $28.91 \pm 0.10$ & $29.47 \pm 0.07$ & $30.35 \pm 0.02$ & $31.17 \pm 0.02$ & $32.20 \pm 0.07$ \\
\hline$T_{\mathrm{r}} \mathrm{VF}$ & $28.20 \pm 0.07$ & $28.89 \pm 0.01$ & $29.56 \pm 0.05$ & $30.56 \pm 0.01$ & $31.24 \pm 0.06$ \\
\hline$T_{\mathrm{r}} \mathrm{WH}$ & $27.94 \pm 0.01$ & $28.39 \pm 0.02$ & $29.15 \pm 0.02$ & $29.93 \pm 0.01$ & $30.69 \pm 0.03$ \\
\hline$T_{\mathrm{r}} \mathrm{MAN}$ & $27.33 \pm 0.19$ & $27.59 \pm 0.47$ & $28.11 \pm 0.20$ & $28.79 \pm 0.20$ & $30.04 \pm 0.11$ \\
\hline
\end{tabular}

Means values $\pm 1 \mathrm{SD}$ of the surface temperatures (in ${ }^{\circ} \mathrm{C}$ ) of the mattress $\left(T_{\mathrm{m}}\right)$ and the right lateral $\left(T_{\mathrm{RW}}\right)$, left lateral $\left(T_{\mathrm{LW}}\right)$, top $\left(T_{\mathrm{TW}}\right)$, front $\left(T_{\mathrm{FW}}\right)$ and rear $\left(T_{\mathrm{BW}}\right)$ walls of the incubator. The heating powers (in $\left.\mathrm{W} \mathrm{m}^{-2}\right)$ supplied to the black $(P)$ and foil-covered $\left(P_{\mathrm{a}}\right)$ manikins, the globe temperature $\left(T_{\mathrm{g}},{ }^{\circ} \mathrm{C}\right)$ and the mean radiant temperatures $\left(T_{\mathrm{r}},{ }^{\circ} \mathrm{C}\right)$ for each approach $(G T$ globe thermometer, $V F$ view factors, $W H$ Wheldon's equation and MAN Manikin method) for the five incubator set temperatures $\left(T_{\mathrm{a}}\right)$ are also indicated

MAN, respectively, $R$ was $10.16 \pm 2.31,14.06 \pm 2.16$, $15.94 \pm 1.96$ and $19.14 \pm 1.85 \mathrm{~W} \mathrm{~m}^{-2}$ in a spread-eagle position (accounting for 35, 43, 47 and $51 \%$ of the whole body heat losses for GT, VF, WH and MAN, respectively) and $\quad 9.06 \pm 2.06, \quad 12.55 \pm 1.93, \quad 14.22 \pm 0.63$ and $17.08 \pm 1.65 \mathrm{~W} \mathrm{~m}^{-2}$ in a relaxed position $(33,41,44$ and $48 \%$ of the whole body heat losses, respectively). For each of the positions, the magnitude of $R$ differed significantly from one method to another $\left(\chi^{2}=39.000, p<0.001\right)$. In spreadeagle position, in comparison with our anthropomorphic manikin, GT $(z=-3.183, p=0.002)$, VF $(z=-3.185$, $p=0.002)$ and WH $(z=-3.185, p=0.002)$ underestimated the degree of body cooling by radiation. We observed the same results for the relaxed position: GT $(z=-3.180$, $p=0.002)$, VF $(z=-3.180, p=0.002)$ and $\mathrm{WH}(z=$ $-3.180, p=0.002)$.

Table 3 shows the metabolic heat production values measured in the 13 preterm neonates. Individual values are reported in order to emphasize the inter-neonate variation in $M_{\text {ref }}$, which is specific to growing organisms (Bach et al. 2000). As described above, $M_{\text {ref }}$ was measured by indirect respiratory calorimetry from $\dot{V}_{\mathrm{O}_{2}}$ and $\dot{V}_{\mathrm{CO}_{2}}$ or calculated by partitional calorimetry $(M)$ using the different $\bar{T}_{r}$ estimates $\left(M_{\mathrm{GT}}, M_{\mathrm{VF}}, M_{\mathrm{WH}}\right.$ and $\left.M_{\mathrm{MAN}}\right)$. The mean values of $\dot{V}_{\mathrm{O}_{2}}$ and $\dot{V}_{\mathrm{CO}_{2}}$ were $8.31 \pm 0.89$ and $8.09 \pm 1.13 \mathrm{ml} \mathrm{min}^{-1} \mathrm{~kg}^{-1}$, respectively (mean respiratory quotient: $0.97 \pm 0.16$ ). Comparisons between calculated and measured data revealed that the $M$ values differed significantly from one method to another $\left(\chi^{2}=38.338, p<0.001\right.$ for the spread-eagle position and $\chi^{2}=40.923, p<0.001$ for the relaxed position). There was no difference between $M_{\text {ref }}$ and $M_{\mathrm{MAN}}$ for the spread-eagle

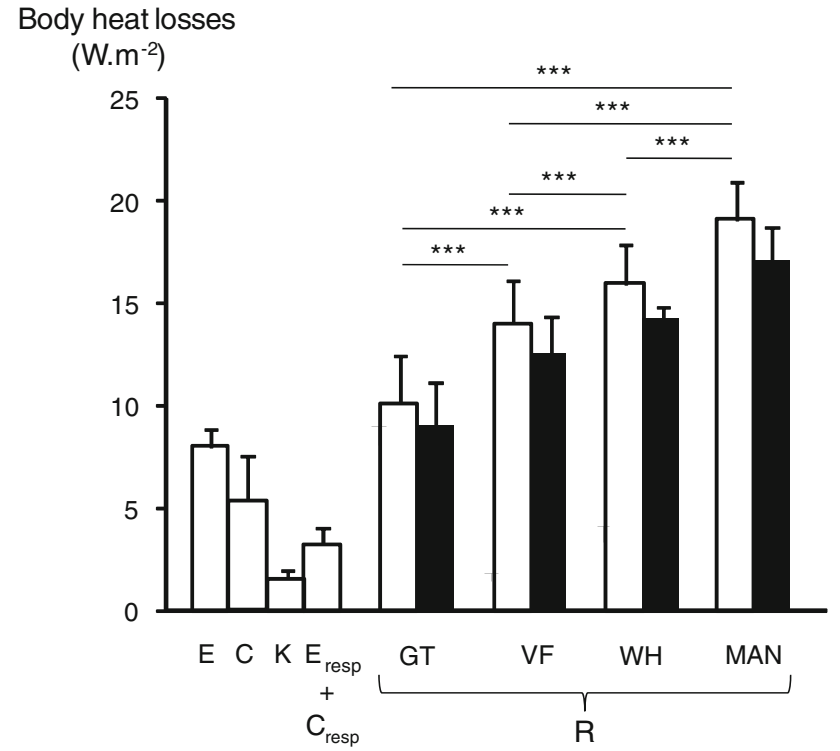

Fig. 1 Mean values $( \pm 1 \mathrm{SD})$ for the different body heat loss modes (calculated by partitional calorimetry) for 13 preterm neonates during clinical tests. Convection $(C)$, respiratory evaporation $\left(E_{\text {resp }}\right)$, skin evaporation $(E)$, conduction $(K)$, respiratory convection $\left(C_{\text {resp }}\right)$ and radiation $(R)$ from the neonate's body are represented by the different columns. GT Globe thermometer, $V F$ view factors, $W$ Wheldon's equation, MAN Manikin. Only the $R$ values differ as a function of the methods used to assess $\bar{T}_{r}$. The sum $C+E+K+C_{\text {resp }}+E_{\text {resp }}$ is constant $\left(18.28 \pm 4.13 \mathrm{~W} \mathrm{~m}^{-2}\right)$. Open and filled bars correspond to $R$ values calculated for neonates in the spread-eagle and relaxed positions, respectively

position (mean difference: $+0.25 \mathrm{~W} \mathrm{~m}^{-2}, z=-0.035$, $p=0.972$ ) or the relaxed position (mean difference: $\left.-1.82 \mathrm{~W} \mathrm{~m}^{-2}, z=-1.233, p=0.221\right)$. A similar result was 
Table 3 Individual metabolic heat production values

\begin{tabular}{|c|c|c|c|c|c|c|c|c|c|}
\hline \multirow[t]{2}{*}{ Neonate } & \multirow[t]{2}{*}{$M_{\text {ref }}$} & \multicolumn{4}{|c|}{ Spread-eagle position $\left(A_{r}=0.74\right)$} & \multicolumn{4}{|c|}{ Relaxed position $\left(A_{r}=0.66\right)$} \\
\hline & & $M_{\mathrm{GT}}$ & $M_{\mathrm{VF}}$ & $M_{\mathrm{WH}}$ & $M_{\mathrm{MAN}}$ & $M_{\mathrm{GT}}$ & $M_{\mathrm{VF}}$ & $M_{\mathrm{WH}}$ & $M_{\text {MAN }}$ \\
\hline 1 & 35.54 & 24.83 & 28.84 & 30.84 & 34.12 & 23.88 & 27.45 & 29.24 & 32.16 \\
\hline 2 & 31.70 & 22.92 & 26.95 & 28.98 & 32.27 & 22.04 & 25.63 & 27.45 & 30.39 \\
\hline 3 & 35.46 & 21.20 & 25.27 & 27.36 & 30.68 & 20.39 & 24.02 & 25.89 & 28.85 \\
\hline 4 & 40.06 & 42.69 & 46.23 & 47.62 & 50.56 & 41.04 & 44.21 & 45.45 & 48.07 \\
\hline 5 & 41.15 & 37.61 & 41.34 & 42.98 & 46.06 & 36.16 & 39.49 & 40.95 & 43.69 \\
\hline 6 & 32.82 & 32.01 & 35.83 & 37.59 & 40.71 & 30.78 & 34.18 & 35.74 & 38.54 \\
\hline 7 & 32.59 & 25.73 & 29.72 & 31.69 & 34.96 & 24.74 & 28.30 & 30.06 & 32.97 \\
\hline 8 & 37.18 & 24.72 & 28.70 & 30.68 & 33.94 & 23.77 & 27.32 & 29.10 & 32.00 \\
\hline 9 & 36.79 & 23.70 & 27.69 & 29.67 & 32.94 & 22.80 & 26.35 & 28.12 & 31.02 \\
\hline 10 & 39.60 & 27.65 & 31.61 & 33.56 & 36.81 & 26.58 & 30.12 & 31.86 & 34.75 \\
\hline 11 & 40.07 & 27.53 & 31.47 & 33.40 & 36.63 & 26.47 & 29.99 & 31.70 & 34.58 \\
\hline 12 & 39.72 & 34.73 & 38.46 & 40.10 & 43.17 & 33.39 & 36.72 & 38.19 & 40.93 \\
\hline 13 & 40.54 & 24.32 & 28.32 & 30.33 & 33.61 & 23.36 & 26.94 & 28.72 & 31.66 \\
\hline Mean & 37.17 & 28.43 & 32.34 & 34.21 & 37.42 & 27.34 & 30.82 & 32.50 & 35.35 \\
\hline SD & 3.32 & 6.44 & 6.29 & 6.08 & 5.97 & 6.19 & 6.05 & 5.64 & 5.77 \\
\hline
\end{tabular}

Individual values (in $\mathrm{W} \mathrm{m}{ }^{-2}$ ) for metabolic heat production $\left(M_{\mathrm{ref}}\right)$, as measured by indirect respiratory calorimetry from $\dot{V}_{\mathrm{O}_{2}}$ and $\dot{V}_{\mathrm{CO}_{2}}$ and calculated $\left(M_{\mathrm{GT}}, M_{\mathrm{VF}}, M_{\mathrm{WH}}\right.$ and $\left.M_{\mathrm{MAN}}\right)$ using partitional calorimetry on the basis of $\bar{T}_{r}$ estimated by each of the four approaches

found for $M_{\mathrm{ref}}$ and $M_{\mathrm{WH}}$ for the spread-eagle position (mean difference: $\left.-2.96 \mathrm{~W} \mathrm{~m}^{-2}, z=-1.712, p=0.087\right)$ but not for the relaxed position (mean difference: $-4.67 \mathrm{~W} \mathrm{~m}^{-2}$, $z=-2.481, p=0.013)$. $M$ values calculated with $\bar{T}_{r}$ estimates from the GT and VF methods were significantly lower than $M_{\text {ref }}$; the mean differences for GT were -8.74 and $-9.83 \mathrm{~W} \mathrm{~m}^{-2}$ for the spread-eagle and the relaxed positions, respectively $(z=-3.040, p=0.002$ and $z=-3.110$, $p=0.002$, respectively) and -4.83 and $-6.35 \mathrm{~W} \mathrm{~m}^{-2}$ for VF for the spread-eagle and the relaxed positions, respectively $(z=-2.411, p=0.016$ and $z=-2.830, p=0.005$, respectively).

\section{Discussion}

One of the strengths of the present study is that we compared the different methods used to calculate mean radiant temperature with clinical data measured on neonates in the NICU. We used the same incubator in the laboratory and in the clinical tests, so that the geometry of the incubator walls did not influence the comparison between physical and clinical data. The present results demonstrate that the values of $\bar{T}_{r}$ differed from one approach to another. The $\bar{T}_{r}$ values calculated with the thermal manikins were always lower than those found with the two other conventional approaches, which therefore underestimated the contribution of the radiant field to whole body heat losses.
When used in a closed incubator, the conventional methods have several serious disadvantages (resulting in differences with respect to the manikin results). In contrast to the situation for a sphere, only a part of the neonate's body surface area participates in radiative heat loss. There is a major difference between a neonate and a globe thermometer in terms of the radiation view factors. The validity of the view factor method can also be questioned, since it relies on several assumptions concerning the shape factors of the neonate's body (represented as a small, flat surface area) and the surrounding surfaces. Moreover, this method does not take account of regional variations in incubator wall temperatures (caused by the presence of localized warm air convection currents near the inner walls). The influence of the incubator's complex thermal environment is thus not accurately reflected by either of these two conventional approaches.

\section{Limitations of the study}

For the two manikins in the spread-eagle position, the magnitudes of $M$ measured did not differ from $M_{\text {ref. }}$. However, for the relaxed position, $M_{\mathrm{WH}}$ differed significantly from the value measured in the clinic. This could have several explanations. Firstly, the measurements for the anthropomorphic thermal manikin were made across the entire surface area; in contrast, Wheldon's method uses spot location. Our anthropomorphic approach also takes account of the surface temperature of the mattress on which the manikin is placed. The mattress has a very large solid 
angle (see Eq. 3) with respect to the model and is thus a major pathway for radiant heat loss. Our model also takes account of the thermal heterogeneity over the manikin's surface area and its complex body shapes, enabling accurate measurement of radiation over the entire body. Secondly, for a neonate in a relaxed position, Wheldon used a fractional radiant area of 0.57 (compared with 0.66 in the present study). Application of this value to the calculation of $\bar{T}_{r}$ (Eq. 8) led to the underestimation (by $0.77^{\circ} \mathrm{C}$ ) of $\bar{T}_{r}$ when the incubator air temperature was set to $33.02^{\circ} \mathrm{C}$. This demonstrates that detailed information on procedures is required before these devices can be used in standards.

Which, then, is the most appropriate method for measuring the radiant temperature in a closed incubator? The validity of the results reported in the present study depends on the accuracy of the parameters governing the heat transfer equations. In the present study, this difficulty was partly resolved using various heat exchange coefficients that had already been experimentally determined with the manikin, thus reducing the uncertainty and the number of empirical assumptions (Chessex et al. 1988; Adams et al. 2000; Lyon and Oxley 2001; Elabbassi et al. 2004; Belghazi et al. 2006; Agourram et al. 2010). Moreover, the use of infrared thermometry enabled us to take account of the intersegment thermal heterogeneity of each neonate and thus obtain a more accurate measurement of the mean skin temperature than with spot measurements at several body sites. The model's performance could be improved further by taking into account more accurate values of the heat loss reduction caused by the diaper. This is particularly relevant, since the diaper's thermal insulation influences the radiative heat loss and so, in turn, the accuracy of the GT and VF methods. In contrast to the situation in adults (Lotens and Pieters 1995; Den Hartog and Havenith 2010), there are no quantitative guidelines on assessing the thermal insulation of specialized protective clothing such as the diaper, which only covers a part of the body skin surface area; this is why the neonate is considered to be naked in today's models of body heat exchange.

The measurements of $\dot{V}_{\mathrm{O}_{2}}$ and $\dot{V}_{\mathrm{CO}_{2}}$ (with a face mask and over short periods of time) may also constitute a limitation. Energy expenditure is more accurately determined over long periods (Elia and Livesey 1988), which take into account variations in the metabolic rate. However, longer measurements would require the neonate's head and trunk to be enclosed in a hood, which necessarily disturbs the infant's heat exchanges with the environment. Bauer et al. (1997) have reported that despite the typical, low respiratory volumes in the neonate, face mask measurements are accurate and interfere less with the neonate's environment than a hood does.
Application of our results and consequences for low-birth-weight neonates

Our results clearly show that the choice of a method for accurate measurement of $\bar{T}_{r}$ is of paramount importance when seeking to model an optimal thermal environment. Regardless of the method used to assess $\bar{T}_{r}$, our results confirmed that (a) radiation is the major source of overall body cooling in closed incubators (accounting for up to 33 and $35 \%$ in relaxed and spread-eagle positions, respectively) and (b) conductive heat loss (3.8-4.5\% of the total body heat loss) only plays a minor role in the neonate's body heat balance when the neonate was nursed on a low-thermal-conductivity plastic foam mattress (Hey and Mount 1967; Swyer 1978; Lyon and Oxley 2001). It should be noted that controlling radiant heat loss is particularly relevant in high-risk, very premature neonates who can only maintain body temperature within a very narrow range of environmental temperatures. Compared with the manikins, the two other approaches underestimated this mode of heat exchange. This underestimate may have an impact on the maintenance of body temperature, body growth and, for high-risk infants, respiratory or cardiac failure. For example, a variation in $\bar{T}_{r}$ of $1.8^{\circ} \mathrm{C}$ (corresponding to the difference of $\bar{T}_{r}$ between MAN and VF approaches for incubator air temperature of $32.01^{\circ} \mathrm{C}$ ) can increase the apnoea frequency by $50 \%$ (Tourneux et al. 2008). In the first few days after birth, when the infant's thermoregulatory defences are not fully mature (Wheldon and Hull 1983) and the body's high surface-to-volume ratio promotes heat loss to the surrounding environment.

If the incubator climate is controlled by an operative temperature (which is a weighted average of $\bar{T}_{r}$ and $T_{\mathrm{a}}$ ), the risk of body cooling is particularly greater when $\bar{T}_{r}$ is calculated from the GT and VF methods. Indeed, the values calculated with these two methods (and then used in the algorithm to control the thermal environment in the incubator) will be too high. Accordingly, the actual value in the incubator will be too low and will increase body heat losses from the neonate to the environment. For example, to further characterize this error and the risk of hypothermia, we calculated the changes in mean body temperature which would reflect the heat storage in the spread-eagle position. With respect to the body heat storage equation $\Delta S=0.277$ $\left(C_{\mathrm{p}} \times \Delta T_{\mathrm{b}} \times \mathrm{W}_{\mathrm{t}}\right) \times A_{\mathrm{D}}^{-1}$ [where $\Delta S$ is the change in body heat storage in $\mathrm{W} \mathrm{m}{ }^{-2} ; C_{\mathrm{p}}$ is the specific thermal capacity of the body tissues $\left(3.494 \mathrm{~kJ} \mathrm{~kg}^{-1}{ }^{\circ} \mathrm{C}^{-1}\right)$ and $\Delta T_{\mathrm{b}}$ is the mean body temperature change in ${ }^{\circ} \mathrm{C}^{-1}$ ] and with respect to the energy expenditure $M_{\text {ref }}$, the underestimations of radiative heat loss reported in Fig. 1 would lead to falls in body temperature of $-0.68,-0.38$ and $-0.23^{\circ} \mathrm{C} \mathrm{h}^{-1}$ when 
GT, VF and WH methods are used, respectively, and just $+0.02{ }^{\circ} \mathrm{C} \mathrm{h}^{-1}$ when calculating $\bar{T}_{r}$ with the MAN method. Under these conditions, the time required to reach the warning threshold of body hypothermia at a body temperature below $36.4^{\circ} \mathrm{C}$, as defined by the American Academy of Pediatrics and College of Obstetrics and Gynecologists (1988) was 53, 95 and 156 min for GT, VF and WH methods, respectively. The risk of body cooling is particularly accentuated using the GT method but is absent for the MAN method.

Although the relative magnitudes of the different heat losses differ from one incubator to another (because of different air flow dynamics and canopy shapes), the conclusion that the manikin technique is particularly reliable for assessing the mean radiant temperature can be drawn solely on the basis of a comparison with the metabolic heat production measured in neonates. The error in the estimation of radiative heat loss is smaller when $\bar{T}_{r}$ is calculated with a manikin which takes account of the neonate's body shape and regional thermal heterogeneity. On the basis of these comparisons, we conclude that the manikin technique is particularly appropriate for measuring $\bar{T}_{r}$ and the radiant heat loss in closed incubators.

\section{Conclusions}

Our present results show that there is a need to draft safety standards for measuring radiant temperature. These standards should seek to estimate all of the neonate's heat exchanges more accurately by taking into account the influence of thermal insulation due to the diaper and/or the mattress. The accurate measurement of these thermal variables may have important, practical implications in the thermal management of neonates, in general, and may be useful for designing more efficient, safer tools, since both the radiant temperature and the air temperature have to be measured in order to optimize the performance of modern incubators and thus potentially reduce morbidity and mortality. Thus, further work will aim at assessing the thermal performance levels of medical devices in more complex environments, e.g. the radiant warmer (in which the radiative heat exchange is primarily related to an overhead radiant source) and the transport incubator (which is used in often cold thermal environments outside the NICU and poses a threat to the survival of small, premature neonates). Additional research on the relationship between thermal insulation (as provided by the diaper) and radiative heat exchange may also lead to sufficiently accurate estimating equations when using simple methods like GT or VF.

The experiments comply with the current laws of the country in which they were performed.
Acknowledgments This work was funded by the French National Research Agency's (ANR) TecSan Program (PRETHERM projet: ANR-08-TECS-016)

Conflict of interest The authors declare that they have no conflict of interest.

Open Access This article is distributed under the terms of the Creative Commons Attribution Noncommercial License which permits any noncommercial use, distribution, and reproduction in any medium, provided the original author(s) and source are credited.

\section{References}

Adams AK, Nelson RA, Bell EF, Egoavil CA (2000) Use of infrared thermographic calorimetry to determine energy expenditure in preterm infants. Am J Clin Nutr 71(4):969-977

Agourram B, Bach V, Tourneux P, Krim G, Delanaud S, Libert JP (2010) Why wrapping premature neonates to prevent hypothermia can predispose to overheating. J Appl Physiol 108(6):16741681

American Academy of Pediatrics, College of Obstetrics, Gynecologists (1988) Guidelines for perinatal care, 2nd edn. American Academy of Pediatrics, Elk Grove Village

American National Standards (1997) Infant incubators. Association for the advance of medical instrumentation, AAMI/CDV 1 II 36, Washington, $\mathrm{p} 62$

Apedoh A, el Hajajji A, Telliez F, Bouferrache B, Libert JP, Rachid A (1999) Mannequin-assessed dry-heat exchanges in the incubatornursed newborn. Biomed Instrum Technol 33(5):446-454

Atherton HD, Dollberg S, Donnelly MM, Perlstein PH, Hoath SB (1994) Computerized temperature control of the low-birthweight infant: a 20-year retrospective and future prospects. Biomed Instrum Technol 28(4):302-309

Bach V, Telliez F, Zoccoli G, Lenzi P, Léké A, Libert JP (2000) Interindividual differences in the thermoregulatory response to cool exposure in sleeping neonates. Eur J Appl Physiol 81(6): $455-462$

Bauer K, Pasel K, Uhrig C, Sperling P, Versmold H (1997) Comparison of face mask, head hood, and canopy for breath sampling in flow-through indirect calorimetry to measure oxygen consumption and carbon dioxide production of preterm infants $<1500$ grams. Pediatr Res 41(1):139-144

Belghazi K, Tourneux P, Elabbassi EB, Ghyselen L, Delanaud S, Libert JP (2006) Effect of posture on the thermal efficiency of a plastic bag wrapping in neonate: assessment using a thermal "sweating" mannequin. Med Phys 33(3):637-644

Bell EF, Rios GR (1983) A double-walled incubator alters the partition of body heat loss of premature infants. Pediatr Res 17(2):135-140

Bolton DP, Nelson EA, Taylor BJ, Weatherall IL (1996) Thermal balance in infants. J Appl Physiol 80(6):2234-2242

Boyd E (1935) The growth of surface area, 1st edn. University of Minnesota Press, Minneapolis

Chessex P, Blouet S, Vaucher J (1988) Environmental temperature control in very low birth weight infants (less than 1000 grams) cared for in double-walled incubators. J Pediatr 113(2):373-380

Curzi-Dascalova L, Mirmiran M (1996) Manuel of methods for recordings and analyzing sleep-wakefulness states in preterm and full-term infants, 1 st edn. INSERM, Paris

Den Hartog EA, Havenith G (2010) Analytical study of the heat loss attenuation by clothing on thermal manikins under radiative heat loads. Int J Occup Saf Ergon 16(2):245-261 
Elabbassi EB, Belghazi K, Delanaud S, Libert JP (2004) Dry heat loss in incubator: comparison of two premature newborn sized manikins. Eur J Appl Physiol 92(6):679-682

Elia M, Livesey G (1988) Theory and validity of indirect calorimetry during net lipid synthesis. Am J Clin Nutr 47(4):591-607

Gagge AP (1937) A new physiological variable associated with sensible and insensible perspiration. Am J Physiol 120:277-287

Ginalski MK, Nowak AJ, Wrobel LC (2007) A combined study of heat and mass transfer in an infant incubator with an overhead screen. Med Eng Phys 29(5):531-541

Ginalski MK, Nowak AJ, Wrobel LC (2008) Modelling of heat and mass transfer processes in neonatology. Biomed Mater 3(3):034113

Hammarlund K, Stromberg B, Sedin G (1986) Heat loss from the skin of preterm and fullterm newborn infants during the first weeks after birth. Biol Neonate 50(1):1-10

Helder KK, Mulder PGH, Van Goudoever JP (1976) Computer assisted newborn intensive care. Pediatrics 57:494-501

Hey EN (1968) Small globe thermometers. J Sci Instrum 1(9):955-957

Hey EN, Mount LE (1967) Heat losses from babies in incubators. Arch Dis Child 42(221):75-84

Jardine DS (1992) A mathematical model of life-threatening hyperthermia during infancy. J Appl Physiol 73(1):329-339

Knobel RB, Holditch-Davis D, Schwartz TA (2010) Optimal body temperature in transitional extremely low birth weight infants using heart rate and temperature as indicators. J Obstet Gynecol Neonatal Nurs 39(1):3-14

Kubaha K, Fiala D, Toftum J, Taki A (2004) Human projected area factors for detailed direct and diffuse solar radiation analysis. Int J Biometeorol 49:113-129

Lewis WK (1922) The evaporative of a liquid into a gas. ASME Trans 4:325-335

Lotens WA, Pieters AM (1995) Transfer of radiative heat through clothing ensembles. Ergonomics 38(6):1132-1155

Lusk G (1928) The element of science and nutrition, 4th edn. WB Sanders, Philadelphia

Lyon AJ, Oxley C (2001) HeatBalance, a computer program to determine optimum incubator air temperature and humidity. A comparison against nurse settings for infants less than 29 weeks gestation. Early Hum Dev 62(1):33-41

Malin SW, Baumgart S (1987) Optimal thermal management for low birth weight infants nursed under high-powered radiant warmers. Pediatrics 79(1):47-54

Museux N, Cardot V, Bach V, Delanaud S, Degrugilliers L, Agourram B, Elabbassi EB, Libert JP (2008) A reproducible means of assessing the metabolic heat status of preterm neonates. Med Phys 35(1):89-100

Oliver TK Jr (1965) Temperature regulation and heat production in the newborn. Pediatr Clin North Am 12:765-779

Perlstein PH, Edwards NK, Atherton HD, Sutherland JM (1976) Computer-assisted newborn intensive care. Pediatrics 57(4):494501

Scopes JW, Ahmed I (1966) Range of critical temperatures in sick and premature newborn babies. Arch Dis Child 41(218):417-419

Silverman WA, Sinclair JC, Agate FJ (1966) The energy cost of minor changes in heat balance of small newborn infants. Acta Pediatr Scand 55:294-300

Standard ISO 7726 (2002) Ergonomics of the thermal environmentInstruments for measuring physical quantities. In: Ergonomie des postes et lieux de travail, tome 2, conception des lieux de travail, Ed Afnor 2002, Saint-Denis-La-Plaine, p 571

Stocks J, Beardsmore C, Helms P (1989) Infant lung function: measurement conditions and equipment. Eur Respir J Suppl 4:123S-129S

Swyer PR (1978) Heat loss after birth. In: Sinclair JC (ed) Temperature regulation and energy metabolism in the newborn. Grune and Stratton, New York, pp 91-127

Tourneux P, Cardot V, Museux N, Chardon K, Leke A, Telliez F, Libert JP, Bach V (2008) Influence of thermal drive on central sleep apnea in the preterm neonate. Sleep 31(4):549-556

Wheldon AE (1982) Energy balance in the newborn baby: use of a manikin to estimate radiant and convective heat loss. Phys Med Biol 27(2):285-296

Wheldon AE, Hull D (1983) Incubation of very immature infants. Arch Dis Child 58(7):504-508 